\title{
Technical and Safety Challenges in Emerging Trends of Near-Field Wireless Power Transfer Industrial Guidelines
}

\author{
Prof. S.Y. Ron Hui \\ Department of Electrical \& Electronic Engineering \\ University of Hong Kong and Imperial College London
}

\begin{abstract}
:
Wireless power transfer (WPT) has reached commercialization stage in consumer electronics and manufacturing industry. New initiatives by industry for expanding the scope of wireless charging in extended short-range and mid-range applications for portable electronics and electric vehicles and are actively underway. In this article, the author addresses some technical challenges in near-field WPT applications on consumer electronics and electric vehicles. In addition, he shares his views on some of the emerging topics about recently proposed industrial guidelines. It is hoped that this article will arouse more interests and discussions on these emerging guidelines among the research and industrial communities so that future industrial standards will cater for all key aspects of user friendliness, health and safety.
\end{abstract}

\section{Introduction}

With the Ampere's law, Faraday's law of electromagnetism established in the nineteenth century, early wireless power transfer (WPT) pioneers, such as Tesla, Hutin and Leblanc [1]-[3], had the required scientific principles to explore near-field WPT through the use of coupled alternating magnetic field. Among early WPT pioneers, Nicola Tesla was undoubtedly the most influential scientist/engineer in WPT research. Tesla was recognized as a highly visionary inventor well ahead of his time [4][5]. He demonstrated that wireless power could be transferred through air based on the principles of using high frequency, magnetic resonance, coils of low resistance and high-quality factor [6]. By 1980s, power electronics and litz wire have provided the needed technologies for realizing low-loss high-frequency power supply for WPT applications. Such historical developments of Litz wires and power electronics explain why research in magnetic resonance based WPT took off for medical implants [6][7] in late 1980s and electric vehicles and inductive power pickups in mid 1990s [8][9]. The mobile phone era in mid 1990s also prompted active research in wireless charging for portable electronics [10]-[15]. Reviews of near-field WPT for a range of applications starting from low-power consumer electronics to relatively high-power inductive power pickup systems in manufacturing industry can be found in [16] and [17] respectively.

Despite the rapid research and development activities in WPT over the last two decades, one common misunderstanding of WPT technology is about the origin of magnetic resonance. Many technical and non-technical stakeholders in WPT industry mistakenly think magnetic resonance for WPT was a recent invention. This mistake has unfortunately propagated into many official documents of industrial guidelines, research publications and technical reviews. Such widespread misconception is partially due to a lack of knowledge in historical developments of WPT, and probably due to publicity raised by a WPT project reported in 2007 [18]. The work in [18] has been examined carefully with electric circuit theory by the authors of [19]-[21]. Their analyses show that the magnetic resonance concept in [18] has been a well-established one in electrical engineering. The historical developments of magnetic resonance over the last century have been summarized and can 
be found in [22]. Reference [22] shows that several important ideas have been the central techniques commonly used for high-efficiency WPT since 1960s by (i) power electronics and (ii) biomedical researchers and engineers in the fields of electrical power conversion and biomedical implants respectively. These important ideas include at least:

1. Magnetic resonance;

2. Use of high $k Q$ product (where $k$ is the mutual coupling coefficient and $Q$ is the quality factor of the coil-resonator) .

Nevertheless, many articles erroneously state that WPT through "magnetic induction" was the traditional technology and through "magnetic resonance" was a recent invention.

Presently, there are three main industrial groups setting guidelines or standards for WPT applications. They are:

(i) the Wireless Power Consortium (WPC) which has launched the world's wireless charging standard "Qi" for portable consumer electronics since 2010,

(ii) the AirFuel Alliance which proposed the 2014 Rezence guidelines for portable consumer electronics and

(iii) the Society of Automobile Engineers (SAE) which set the 2016 WPT guidelines for electric vehicles.

This article focuses on existing and emerging industrial guidelines and standards of WPT applications. The author shares his views on some limitations of these standards and guidelines, and suggests some alternative solutions and directions. The aim of the article is to arouse more interests and discussions on these emerging standards and guidelines among the research and industrial communities in WPT.

\section{Wireless Power Consortium}

\section{A Background}

The availabilities of modern power electronics in 1980s and Litz wires since 1960s have provided the needed technologies for high-efficiency WPT in the last two decades. The dawn of the mobile era in 1980s was a key factor triggering research into wireless charging pads (i.e. planar WPT technologies). With different mobile phone manufacturers using their own proprietary charging protocols in the 1990s, there was an obvious need from the consumers' point of view that a common charging standard should be adopted. In early 2000s, the "horizontal flux" approach [23][24] and the "vertical flux" approach [25] were proposed for wireless charging pad systems. The horizontal flux approach can be visualized as compressing the winding structure of a rotating machine into a pancake shape (Fig.1). As a result, the alternating magnetic flux flows "horizontally" above and below the surface of the wireless charging pad. Because the plane of the receiver coil should be perpendicular to the lines of magnetic flux, the receiver coil has to be placed vertically to the charging pad surface (as shown in Fig.1) to receive the horizontal flux. The need for a vertical receiver coil in a portable device is against the requirement of slim design (with minimal thickness) of the mobile phones. In addition, a thick layer of ferrite is needed below the charging platform to confine the magnetic flux. On the contrary, the vertical flux approach [25][26] is based on planar winding arrays below the wireless charging surface (Fig.2). The magnetic flux flows vertically from the charging surface. The horizontal receiver coil can always pick up the vertical flux emitted from the charging pad surface as shown in Fig.2. Therefore, the vertical flux approach has no restriction on the orientation of the planar receiver coil, which is suitable for embedment into slim design of mobile phones. In 2008, a group 
of electronics companies formed the Wireless Power Consortium (WPC) with the objective of forming a common wireless charging protocol for portable consumer electronics. The WPC has selected the vertical flux approach as the basis of its wireless power standard [27].



Fig.1 Concept of an inductive charging pad based on the horizontal-flux approach [23][24]

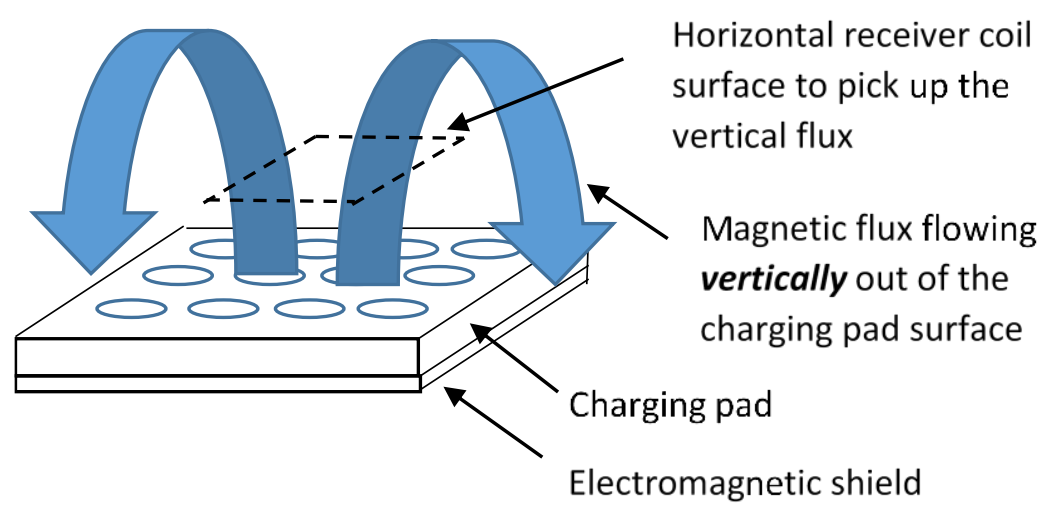

Fig.2 Concept of a wireless charging pad based on the vertical-flux approach [25][26]

B The Evolving "Qi” Standard by Wireless Power Consortium

Founded initially with 8 companies in November 2008 [28], the Wireless Power Consortium (WPC) has grown to include over 210 companies worldwide by June 2017. With Apple Inc. joining WPC in 2017, essentially all major smart phone manufacturers have joined the WPC. The growth of the WPC membership since 2008 is shown in Fig.3. 




Fig.3 Growth of membership of the Wireless Power Consortium (Courtesy of Mr. Menno Treffers)

The WPC launched the world's first wireless charging standard "Qi" (pronounced as Chee) in August 2010. So far, this is the most successful wireless charging standard in commercial terms because over 790 "Qi-certified" products have been registered with WPC by October 2016, let alone many other products claimed to be Qi-compatible, Qi-compliant or Qi-approved. The rapid growth of Qi-certified products can be compared with other technologies such as CD-R, GSM, WiFi and Bluetooth. The X-axis of Fig.4 is the number of years since the standards of these technologies were launched. The growth of Qi products is comparable with that of Bluetooth products, and is faster than those of CD-R, GSM and WiFi.

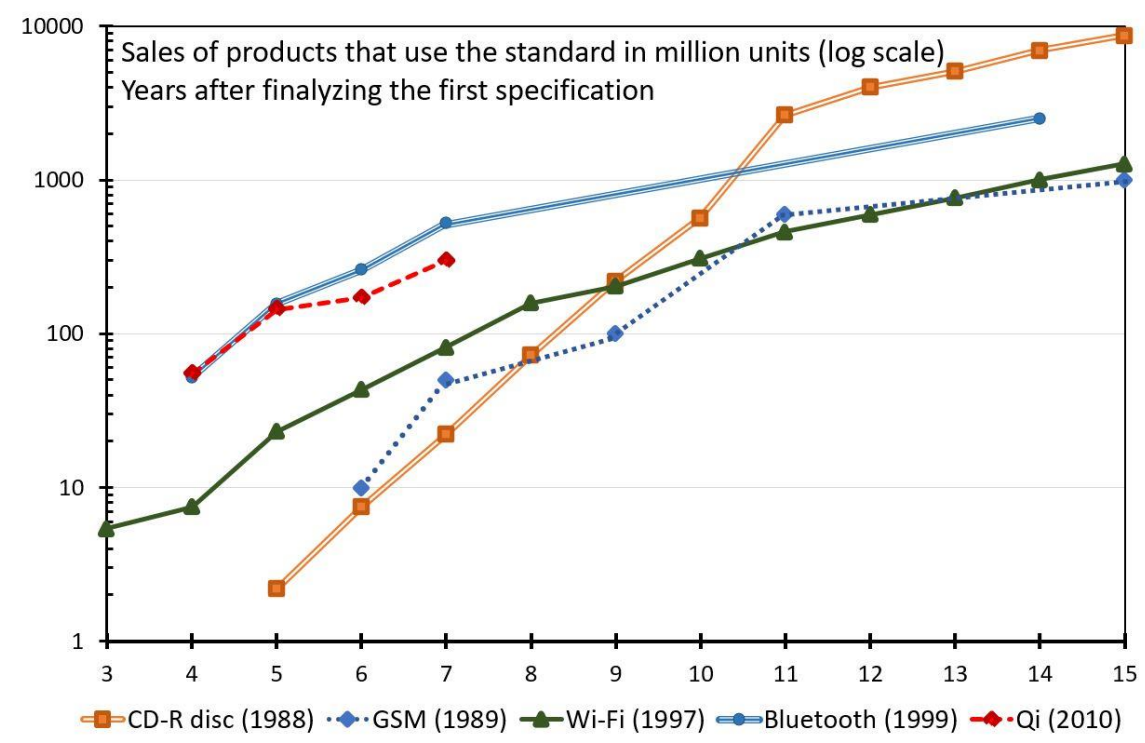

Fig.4 Growths of product sales of several technologies since their standards were launched (Courtesy of Mr. Menno Treffers)

Based on the information from the WPC website [27], the Qi standard has evolved from version 1.0, 1.1 to 1.2. The main features of these three versions of the standard are tabulated in Table 1. In the early stage of WPC formation, founding company members put safety as the top priority 
while maintaining high energy efficiency and user-friendliness. The first version of Qi stressed the importance of minimization of human exposure to the electromagnetic fields generated by the charging pads. The safety aspect was extended to the detection of foreign objects in later versions. The expanding applications and power capabilities of wireless charging are reflected from the evolution of the Qi standard.

The current version of the Qi specification has version number 1.2.3 [37]. The operating frequency range of Qi is within $87 \mathrm{kHz}$ to $205 \mathrm{kHz}$. This frequency range has been adopted in switched mode power supplies for over 3 decades. System energy efficiency above $70 \%$ can generally be achieved at full load. It is important to note that the lower frequency has been changed from 110 $\mathrm{kHz}$ to $87 \mathrm{kHz}$. The reason is due to the increasing use of Qi wireless charging pads inside new vehicles, which need to meet stringent electromagnetic compatibility (EMC) requirements set for automobile applications.

The Qi standard covers primarily short-range WPT applications. The receiver coils of the loads are placed in close proximity of the transmitter coils. The transmission distance is up to about $4 \mathrm{~cm}$. Consequently, the magnetic flux for WPT is essentially enclosed and thus human exposure to electromagnetic radiation is usually not an issue. The recent inclusion of foreign object detection (FoD) is another important step forward in enhancing safety [29]. WPC takes a backward compatibility approach so that products certified with previous versions of the Qi standard can still be used with new products certified with the latest version of the standard. Fig.5 shows the numbers of Qi certifications issued for the 3 versions of Qi.

Table 1 Summary of the key features of the versions of Qi standard [27]

\begin{tabular}{|c|c|}
\hline \multicolumn{2}{|c|}{ Version 1.0} \\
\hline & $\begin{array}{l}\text { Qi transmitter delivers } 5 \text { Watt power into a Qi phone. } \\
\text { Choices of transmitter designs include single coil transmitter, coil array } \\
\text { transmitter, and moving coil transmitter. } \\
\text { High flexibility in design of Qi receivers } \\
\text { Limited flexibility in the design of Qi transmitters }\end{array}$ \\
\hline \multicolumn{2}{|c|}{ Version 1.1} \\
\hline & $\begin{array}{l}\text { Increased design freedom for transmitters. One can now choose between } 12 \\
\text { different transmitter specifications. } \\
\text { Increased sensitivity of "Foreign Object Detection". This prevents heating of } \\
\text { metal objects in the neighborhood of an active transmitter. } \\
\text { The possibility to power a Qi transmitter with a USB charger. }\end{array}$ \\
\hline \multicolumn{2}{|c|}{ Version 1.2} \\
\hline & $\begin{array}{l}\text { Fast charging. The possibility for transmitters to deliver up to } 15 \text { Watt power } \\
\text { and the option for receivers to obtain up to } 15 \text { Watt. } \\
\text { An improved thermal test for transmitters } \\
\text { Improved timing requirements } \\
\text { Changed limits for Foreign Object Detection } \\
\text { Optional unique identifier for power receivers (WP-ID) }\end{array}$ \\
\hline
\end{tabular}






Fig.5 Numbers of Certifications issued for the 3 versions of Qi

\section{Technical Challenges and The Author's Personal Views}

While it is pleasing to see the WPC grows from strength to strength, it is necessary for WPC members to set sights on emerging WPT applications. The Qi standard has been modified to increase the power capability and transmission distance (although still within the short-range regime) in order to cover more applications. This paves the way for more Qi-compatible products such as new furniture with embedded Qi-certified charging pads (such as the desks and lamp stands with embedded wireless charging pads marketed by IKEA). The increased transmission distance caters for the extended WPT distance through the thickness of the tables and desks. If such products are widespread in hotel rooms, travellers do not have to carry many chargers and power sockets of various countries.

With more and more small portable electronic devices such as smart watches and Bluetooth earpieces that need wireless charging, the WPC should consider increasing the operating frequency range to a higher level (e.g. $500 \mathrm{kHz}$ ) in order to reduce the sizes of the transmitter and receiver modules. This change in frequency may affect the backward compatibility policy. But for long-term success of Qi, a wider coverage of product forms is essential.

The WPC is expanding its standards to cover high-power kitchen equipment. Because of the relatively high power involved, localized power transfer (i.e. with the magnetic flux paths enclosed with electromagnetic shields) and free-positioning are key features catering for safety and userconvenience respectively.

\section{AirFuel Alliance}

\section{A Background of AirFuel Alliance and the Rezence Guidelines}

After the establishment of the WPC, alternative organizations have been formed with the hope of setting up wireless charging standards to cover other forms of WPT applications. Formed in 2012, the Power Matters Alliance (PMA) and the Alliance for Wireless Power (A4WP) were two examples. In 2015, PMA and A4WP merged together to form the AirFuel Alliance (AFA) [30]. By June 2017, there are about 100 company members listed in the membership of the AFA. There are overlaps of memberships between the AFA and the WPC. At the time of writing this article, the AFA retains the Nov. 2014 Version 1.3 of the A4WP specification. (A4WP-S-0001 v1.3) [31]. 
Different from the WPC which focuses primarily short-range applications with minimized human exposure to ac magnetic field, the AFA was set up to develop and maintain the standards for a form of wireless power that allows additional spatial freedom. The aim is to develop a standard that could simultaneously charge a multiple devices, ranging from low-power Bluetooth devices to laptop computers and also covering both short-range and mid-range applications. An illustration of this objective is shown in Fig.6.

Some other important features of the technologies being promoted by the AFA are the choices of $6.78 \mathrm{MHz} \pm 15 \mathrm{kHz}$ as the operating frequency for power transfer and $2.4 \mathrm{GHz}$ for control and communication signals. In principle, previous WPT technologies developed over the century can be applied to both relatively low frequency operations such as $110 \mathrm{kHz}-205 \mathrm{kHz}$ for WPC or $6.78 \mathrm{MHz}$ $\pm 15 \mathrm{kHz}$ for AFA. But the use of a much higher frequency in AFA is to increase $Q$ for a small mutual coupling coefficient $k$ so that a reasonably high $k Q$ product can be maintained.



Fig.6 An illustration of the WPT concept with spatial freedom

\section{B Health Concerns on Human Exposure to Magnetic Field at $7 \mathrm{MHz}$}

Compared with WPC which focuses primarily on short-range WPT applications, AFA chooses a much higher WPT frequency which enables higher compactness of the power and magnetic circuits and a high $Q$ factor. As explained previously, increasing the value of $Q$ allows the mutual coupling to decrease for a given $k Q$ product. A small value of $k$ implies a relatively long transmission distance for WPT, making it possible to increase spatial freedom. However, the idea of increasing spatial freedom (Fig.6) also implies the requirements of human exposure to ac magnetic field.

The main concern of using magnetic field at $6.78 \mathrm{MHz}$ lies not only in the technical performance of the WPT technologies available today, but in the potential health hazards raised recently by quantum biologists about the adverse effects of ac magnetic field at $7 \mathrm{MHz}$ on cell growth. In 2014, practical evidence was presented in [32] to show that even a weak magnetic field of $10 \mu \mathrm{T}$ at $7 \mathrm{MHz}$ could enhance cell proliferation. Note that an ac magnetic field of $10 \mu \mathrm{T}$ is considered to be weak because the static magnetic field of the earth is about $45 \mu \mathrm{T}$. The authors of [31] suggest that magnetic field at $7 \mathrm{MHz}$ could influence the electronic spins of cells to form radicals. The authors of [32] criticize the existing safety regulations which only consider the thermal stress on cells based on the specific absorption rate (Watt per kilogram of tissue) as inadequate. They concluded that "In contrast to the spin-pair mechanism, specific absorbed radiation (SAR) measurements of macroscopic tissue heating represent a nä̈ve approach to bio-magnetic RF- interactions because it ignores 
nanoscale physics and spin chemistry, which can potentially have profound biological effects." Following up the work in [32], the authors of [33] provide possible explanations for observed changes in growth rates of cancer cells and radical concentration upon exposures to magnetic fields below the ICES and ICNIRP reference levels.

\section{Technical Challenges and the Author's Views}

While spatial freedom in WPT is a highly attractive user-convenience feature, safety and energy efficiency are also important. If wireless power transfer covers a large space in which human exposure to the ac magnetic field cannot be avoided, the health concerns raised by quantum biologists must be addressed. It is therefore important for international regulatory bodies to re-examine existing health and safety regulations in view of the new evidence because $7 \mathrm{MHz}$ is close to the Industrial, Scientific and Medical (ISM) radio band of $6.78 \mathrm{MHz}$ (which happens to be the operating frequency selected by the AFA).

It should be noted that some researchers with Radio-Frequency (RF) background tend to ignore the power losses in the power sources in their calculation of the power transmission energy efficiency. Regardless of short-range or mid-range WPT, the overall energy efficiency drops rapidly with the transmission distance even if magnetic resonance is adopted. The spatial freedom suggested in Fig. 6 will unavoidably lead to poor energy efficiency in addition to the human exposure to ac magnetic field problem.

The author believes that using 6.78 MHz for short-range applications in which the magnetic flux is enclosed or shielded (like the application framework in the WPC) should not encounter the same potential health and energy efficiency issues. The choice of operating frequencies does not affect the validity of many existing WPT technologies in terms of the technical viabilities. Stakeholders in the WPT industry should consider a common standard that addresses both technical performance and health and safety concerns of consumers.

\section{SAE TIR J2954 Guidelines for Wireless Charging of Plug-In Electric Vehicles}

\section{A Background}

SAE International, initially established as the Society of Automotive Engineers, is a professional association and standards-developing organization for engineering professionals in various industries. In May 2016, SAE launched SAE TIR J2954 as an industry-wide specification guideline that defines acceptable criteria for interoperability, electromagnetic compatibility, minimum performance, safety and testing for wireless charging of light duty electric and plug-in electric vehicles [34].

\section{$B$}

\section{SAE TIR J2954 Guidelines}

The current version addresses unidirectional charging from grid to vehicle (Fig.6). Bidirectional energy transfer is not covered. This guideline calls for a common operating frequency of $85 \mathrm{kHz}$, which is easily manageable with existing power electronics technology even at $10 \mathrm{~kW}$. It proposes four classes of wireless power transfer: $3.7 \mathrm{~kW}, 7.7 \mathrm{~kW}, 11.0 \mathrm{~kW}$, and $22.0 \mathrm{~kW}$. It is intended to be used for stationary applications. Dynamic wireless charging will most likely be considered in future guidelines when dynamic wireless charging technology becomes more mature.

Fig. 7 shows the basic concept underlined by the SAE guidelines. The receiver coil is placed on the bottom of the car chassis and the transmitter module is placed on the floor. The transmission distance is in the range of $100 \mathrm{~mm}$ for Class $\mathrm{Z} 1$ to up to $250 \mathrm{~mm}$ for Class Z3. 




Fig.7 SAE J2954 WPT Flow diagram (redrawn from [34])

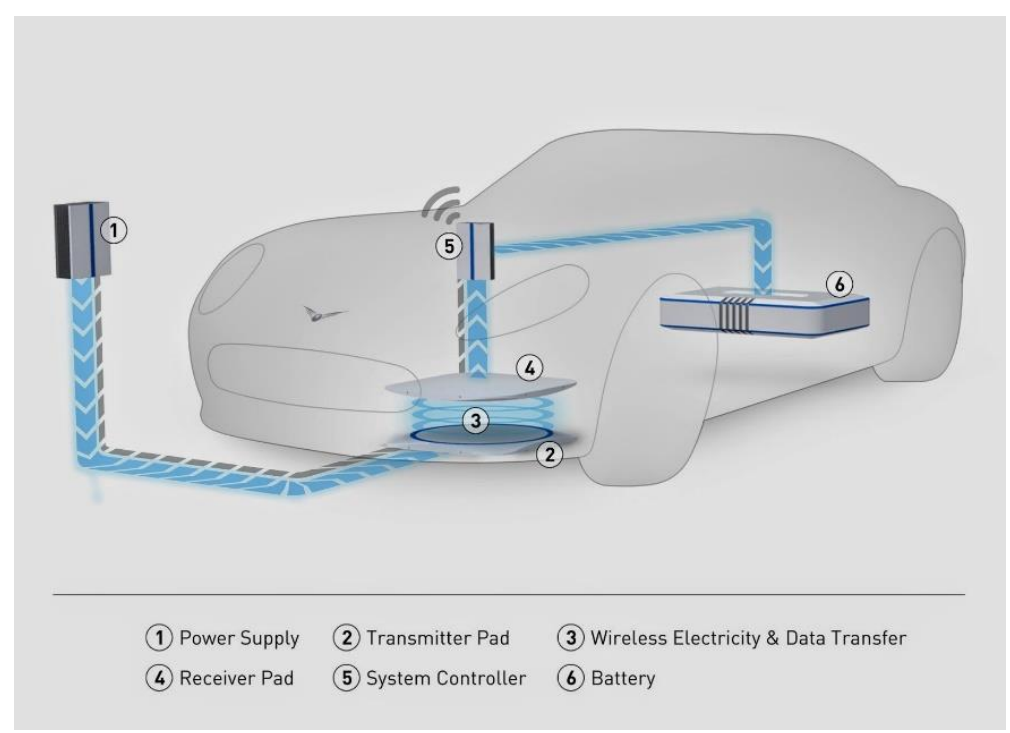

Fig.8 Typical concept of wireless charging of electric vehicle with receiver pad mounted in the bottom of the vehicle chassis [34]

\section{Technical Challenges and the Author's Views} 2016).

In the opinion of the author, there are several major problems in the SAE guidelines (J2954 May

(1) Firstly, because the receiver coil is assumed to be embedded in the bottom of the vehicle chassis (Vehicle Assembly) and the transmitter coil (inside the Ground Assembly) is assumed to be placed on the floor below the vehicle, there is a considerably large gap between the transmitter and receiver coils. In the SAE 2016 guidelines, such ground clearance varies from $100 \mathrm{~mm}$ for Class Z1 to up to $250 \mathrm{~mm}$ for Class Z3. Since the WPT energy efficiency is inversely proportional to the transmission distance, a considerably large transmission distance will lead to relatively low energy efficiency. This is why existing WPT systems following the SAE 2016 guidelines typically have overall system energy efficiency less than $90 \%$ when the transmitter and receiver coils are in good alignment.

(2) Secondly, with a large transmission distance up to $250 \mathrm{~mm}$, there is another problem of misalignment between the transmitter and receiver coils. Misalignment is another factor leading to poor WPT energy efficiency.

(3) Thirdly, the large transmission distance implies magnetic flux leakage issue in the surrounding between the transmitter and receiver coils. Foreign objects or pet animals in the surrounding may be subject to the exposure of strong magnetic field. 
(4) Fourthly, debris, stones and chips may hit the receiver pad at high speed when the cars move at high speed on the roads. It is difficult to ensure good conditions of the receiver pad and to monitor its conditions (because the receiver pad is placed under the car).

It is better to eliminate the problems than to spend resources to solve unnecessary problems. The author believes that it is better to place the receiver pad on the roof of the vehicle (Fig.9), while the transmitter pad is mechanically placed on top of the receiver pad with the help of either an automatically position-guided mechanical arm or a manually adjustable mechanical arm (Fig.10) [35]. In order to ensure minimization of human exposure of the magnetic field and exposure of magnetic field to foreign objects, it is necessary to enclose the magnetic field between the transmitter and receiver pads. Also, it is also more convenient to have thin structures, particularly for the receiver pad that has to be installed in the roof of the vehicle chassis. In this way, the transmission distance between the transmitter and received pads can be kept as small as possible (typically a few millimetres to at most a few tens of millimetres) for achieving high energy efficiency.

Since WPT occurs between the bottom side of the transmitter pad and the top side of the receiver pad, it is desirable to prevent magnetic field from emitting through the top side of the transmitter pad and the bottom side of the receiver pad. The thin double-layer electromagnetic shield [36] can be placed on top of the transmitter pad and the bottom of the receiver pad. In this way, the ac magnetic field between the transmitter and received pads can be sandwiched or enclosed by the electromagnetic shields for minimizing human exposure to the magnetic field and heating problem of nearby foreign objects. Because the double-layer EM shield can have a slim design, it can easily be embedded in the roof of the car chassis. A brief comparison of the author's proposal and the SAE 2016 guidelines is included in Table 2.



Fig.9 An example of a vehicle with the proposed water-proof receiver pad on the roof of the vehicle for receiving wireless power [35] 




Fig.10 An example of a vehicle with the proposed water-proof receiver pad on the roof of the vehicle for receiving wireless power [35]

Table 2: Comparison of the some features the SAE 2016 Guidelines and the new proposal

\begin{tabular}{|c|c|c|c|}
\hline & SAE 2016 Guidelines [34] & New Proposal [35] & Advantages of New Proposal \\
\hline $\begin{array}{l}\text { Receiver pad } \\
\text { position }\end{array}$ & $\begin{array}{l}\text { Mounted in the bottom of } \\
\text { the vehicle chassis. }\end{array}$ & $\begin{array}{l}\text { Placed on the roof of } \\
\text { the vehicle chassis }\end{array}$ & $\begin{array}{l}\text { - } \quad \text { Easy access by the users or the } \\
\text { automated positioning system. } \\
\text { Less likely to be hit by debris in } \\
\text { the road. } \\
\text { - Water-proof and electrically- } \\
\text { insulated surface of the receiver } \\
\text { pad easily monitored and } \\
\text { maintained. } \\
\text { Location far from foreign } \\
\text { objects and pets on the ground }\end{array}$ \\
\hline $\begin{array}{l}\text { Transmitter } \\
\text { pad position }\end{array}$ & Placed on the ground & $\begin{array}{l}\text { Placed directly on top } \\
\text { of the receiver pad on } \\
\text { the roof of the vehicle. }\end{array}$ & 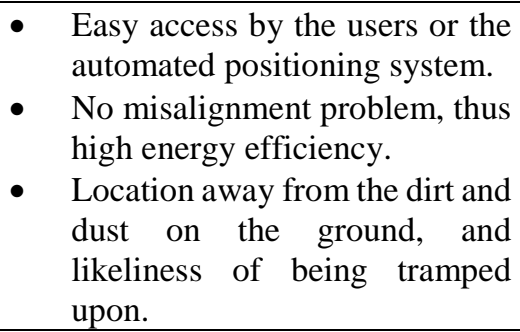 \\
\hline $\begin{array}{l}\text { Transmission } \\
\text { distance }\end{array}$ & $100 \mathrm{~mm}$ to $250 \mathrm{~mm}$ & $\begin{array}{l}\text { Thickness of the water- } \\
\text { proof and electrical } \\
\text { insulated materials of } \\
\text { the transmitter and } \\
\text { receiver pads } \\
\text { (A few millimetres to } \\
\text { less than a few tens of } \\
\text { millimetres.) }\end{array}$ & $\begin{array}{l}\text { - } \text { High magnetic coupling } \\
\text { coefficient. } \\
\text { - } \quad \text { High energy efficiency. } \\
\text { - Less magnetic flux leakage and } \\
\text { associated problems such as } \\
\text { human exposure and heating of } \\
\text { nearby foreign objects. } \\
\text { No danger to pets under the } \\
\text { vehicle. }\end{array}$ \\
\hline $\begin{array}{l}\text { Misalignment } \\
\text { problem }\end{array}$ & yes & $\begin{array}{ll}\text { No } & \text { misalignment } \\
\text { problem } & \end{array}$ & - $\quad$ No misalignment problem \\
\hline
\end{tabular}




\begin{tabular}{|l|l|l|l|}
\hline $\begin{array}{l}\text { Parking } \\
\text { precision } \\
\text { requirements }\end{array}$ & Yes & No such requirement & No such requirement \\
\hline $\begin{array}{l}\text { Human } \\
\text { exposure to } \\
\text { magnetic field }\end{array}$ & serious & insignificant & $\bullet$ Excellent safety features \\
\hline
\end{tabular}

\section{Issues of Human Exposure to Electromagnetic Fields}

Having pointed out new concerns raised by quantum biologists about safety of human exposure to human bodies in Section IV-B, it is necessary to understand existing standards and regulations in relation to WPT applications. The relevance of these standards depends the product categories such as information technology, lighting, healthcare, automative and household appliance. For example, mobile phones and their charging pads normally fall into the category of household appliance. The EMC involves at least two aspects. The first aspect is the EMC of the equipment. For the equipment, the standards in Table 3 govern the maximum limits of EM field emission and the minimum immunity to the EM fields.

Table 3 Some relevant standards for household appliances

\begin{tabular}{|l|l|}
\hline Region & Regulations \\
\hline World & CISPR-14-1, CISPR 14-2 \\
\hline United States & FCC 47 CFR part 15 \\
\hline Europe & EN 55014-1, EN 55014-2 \\
\hline
\end{tabular}

The second EM aspect is related to human exposure to EM fields. The two major regulatory bodies are the International Commission on Non-Ionizing Radiation Protection (ICNIRP) and the Institute of Electrical and Electronic Engineers (IEEE). The standards usually provide the (i) basic restrictions and (ii) reference level. The basic restrictions are directly related to the health effects and must not be violated. The reference levels are the maximum permissible exposure values. They are provided to allow practical assessments on whether the basic restrictions are likely to be violated or not. EM field exposure below the reference levels implies that the basic restrictions are not violated. But EM field exposure above reference levels does not necessarily mean that the basic restrictions must be violated.

Table 4 tabulates the ICNIRP (1998) basic restrictions for the general public exposure to timevarying electric and magnetic fields. The reference levels are included in Fig11. It can be seen that the reference levels generally decrease with increasing frequency. For short-range applications (such as the Qi standard that uses $87 \mathrm{kHz}$ to $205 \mathrm{kHz}$ ), it is easier to meet the ICNIRP (1998) standard because the operating frequency is not higher than $205 \mathrm{kHz}$. A high frequency of $6.78 \mathrm{MHz}$ is selected in the Rezence guidelines to obtain a high $k Q$ product in order to overcome the mid-range transmission distance. The challenge in meeting the required standard becomes much higher. Fig.12 shows the IEEE reference levels for exposure to time varying EM fields. Similar to the ICNIRP standard, the reference levels generally decrease with increasing frequency.

The ICNIRP guidelines for the low frequency range from $1 \mathrm{~Hz}$ to $100 \mathrm{kHz}$ were updated in 2010 [38]. Table 5 tabulates the limits for the general public exposure. The focus lies in the very low frequency range. For frequency higher than $100 \mathrm{kHz}$, the footnote of the Table 4 states that "radiofrequency specific reference levels need to be considered additionally". Again, these updates have not considered the effects of the EM fields on the cells down to the quantum electron spins level. 
Table 4 ICNIRP (1998) Basic restrictions for general public to time varying EM fields up to $10 \mathrm{GHz}$

\begin{tabular}{|l|c|c|c|c|}
\hline \multicolumn{1}{|c|}{ Frequency } & $\begin{array}{c}\text { Current density } \\
\text { (head and trunk) } \\
\mathrm{mA} / \mathrm{m} 2(\mathrm{rms})\end{array}$ & $\begin{array}{c}\text { Average SAR } \\
\text { (whole body) } \\
\text { W/kg }\end{array}$ & $\begin{array}{c}\text { Localized SAR } \\
\text { (head and trunk) } \\
\text { W/kg }\end{array}$ & $\begin{array}{c}\text { Localized SAR } \\
\text { (limbs) } \\
\text { W/kg }\end{array}$ \\
\hline Up to $1 \mathrm{~Hz}$ & 8 & & & \\
\hline $1 \mathrm{~Hz}-4 \mathrm{~Hz}$ & $8 / f$ & & & \\
\hline $4 \mathrm{~Hz}-1000 \mathrm{~Hz}$ & 2 & & & \\
\hline $1 \mathrm{kHz}-100 \mathrm{kHz}$ & $f / 500$ & & & \\
\hline $100 \mathrm{kHz}-10 \mathrm{MHz}$ & $f / 500$ & 0.08 & 2 & 4 \\
\hline $10 \mathrm{MHz}-10 \mathrm{GHz}$ & & 0.08 & 2 & 4 \\
\hline
\end{tabular}

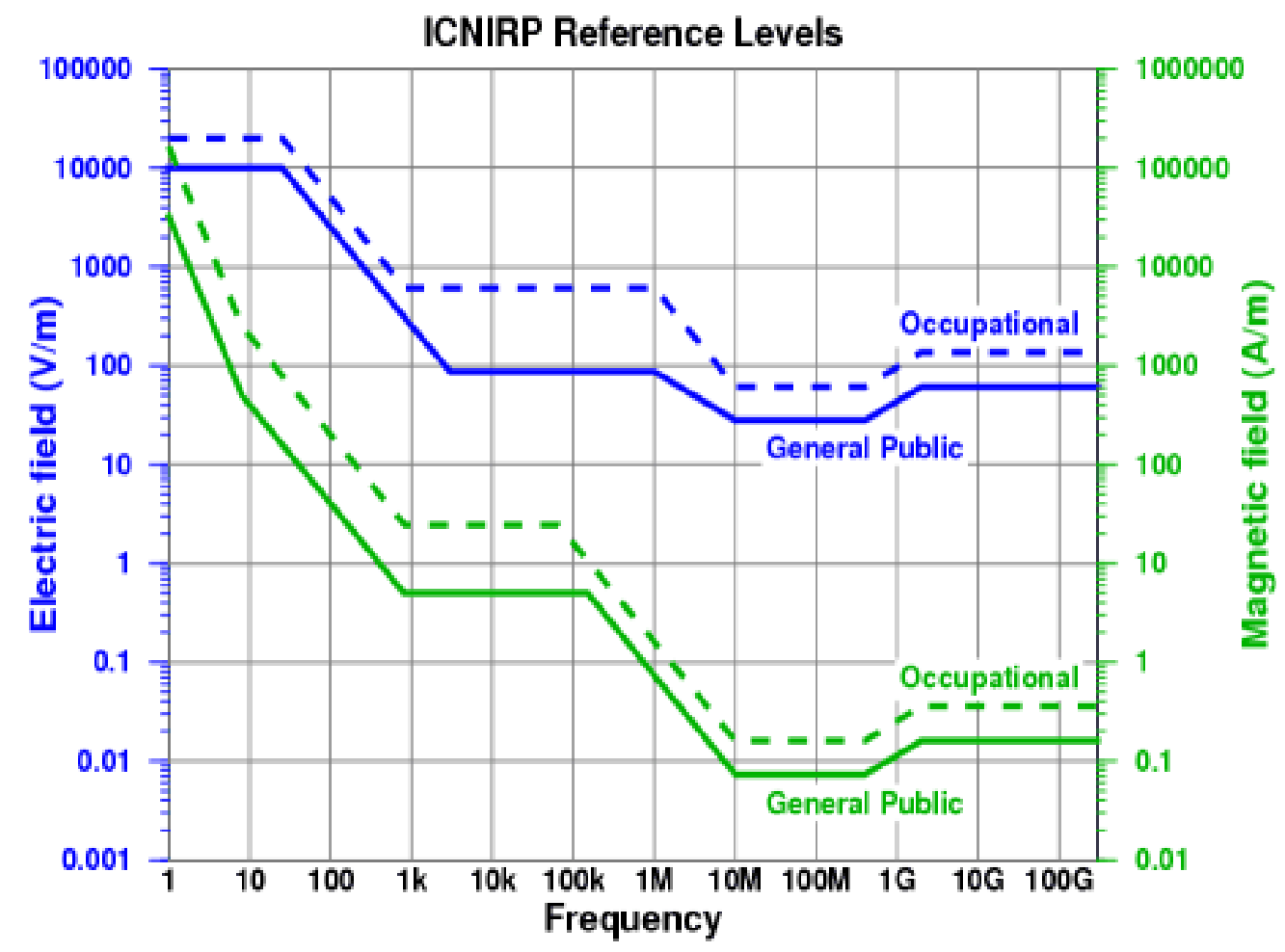

Fig.11 ICNIRP (1998) reference levels of the human exposure to the electric and magnetic fields

Table 5 ICNIRP (2010) reference levels for general exposure to time-varying electric and magnetic fields (unperturbed rms values)

\begin{tabular}{|l|c|c|c|}
\hline Frequency range & $\begin{array}{c}\text { Electric field strength } \\
\left(\mathrm{kV} \mathrm{m}^{-1}\right)\end{array}$ & $\begin{array}{c}\text { Magnetic field } \\
\text { strength }\left(\mathrm{A} \mathrm{m}^{-1}\right)\end{array}$ & $\begin{array}{c}\text { Magnetic flux density } \\
(\mathrm{T})\end{array}$ \\
\hline $1 \mathrm{~Hz}-8 \mathrm{~Hz}$ & 5 & $3.2 \times 10^{4} / \mathrm{f}^{2}$ & $4 \times 10^{-2} / \mathrm{f}^{2}$ \\
\hline $8 \mathrm{~Hz}-25 \mathrm{~Hz}$ & 5 & $4 \times 10^{3} / \mathrm{f}$ & $5 \times 10^{-3} / \mathrm{f}$ \\
\hline $25 \mathrm{~Hz}-50 \mathrm{~Hz}$ & 5 & $1.6 \times 10^{2}$ & $2 \times 10^{-4}$ \\
\hline $50 \mathrm{~Hz}-400 \mathrm{~Hz}$ & $2.5 \times 10^{2} / \mathrm{f}$ & $1.6 \times 10^{2}$ & $2 \times 10^{-4}$ \\
\hline $400 \mathrm{~Hz} 3 \mathrm{kHz}$ & $2.5 \times 10^{2} / \mathrm{f}$ & $6.4 \times 10^{4} / \mathrm{f}$ & $8 \times 10^{-2} / \mathrm{f}$ \\
\hline $3 \mathrm{kHz}-100 \mathrm{kHz}$ & $8.3 \times 10^{-2}$ & 21 & $2.7 \times 10^{-5}$ \\
\hline
\end{tabular}

Note:

- $\mathrm{f}$ in $\mathrm{Hz}$.

- In the frequency range above $100 \mathrm{kHz}, \mathrm{RF}$ specific reference levels need to be considered additionally. 


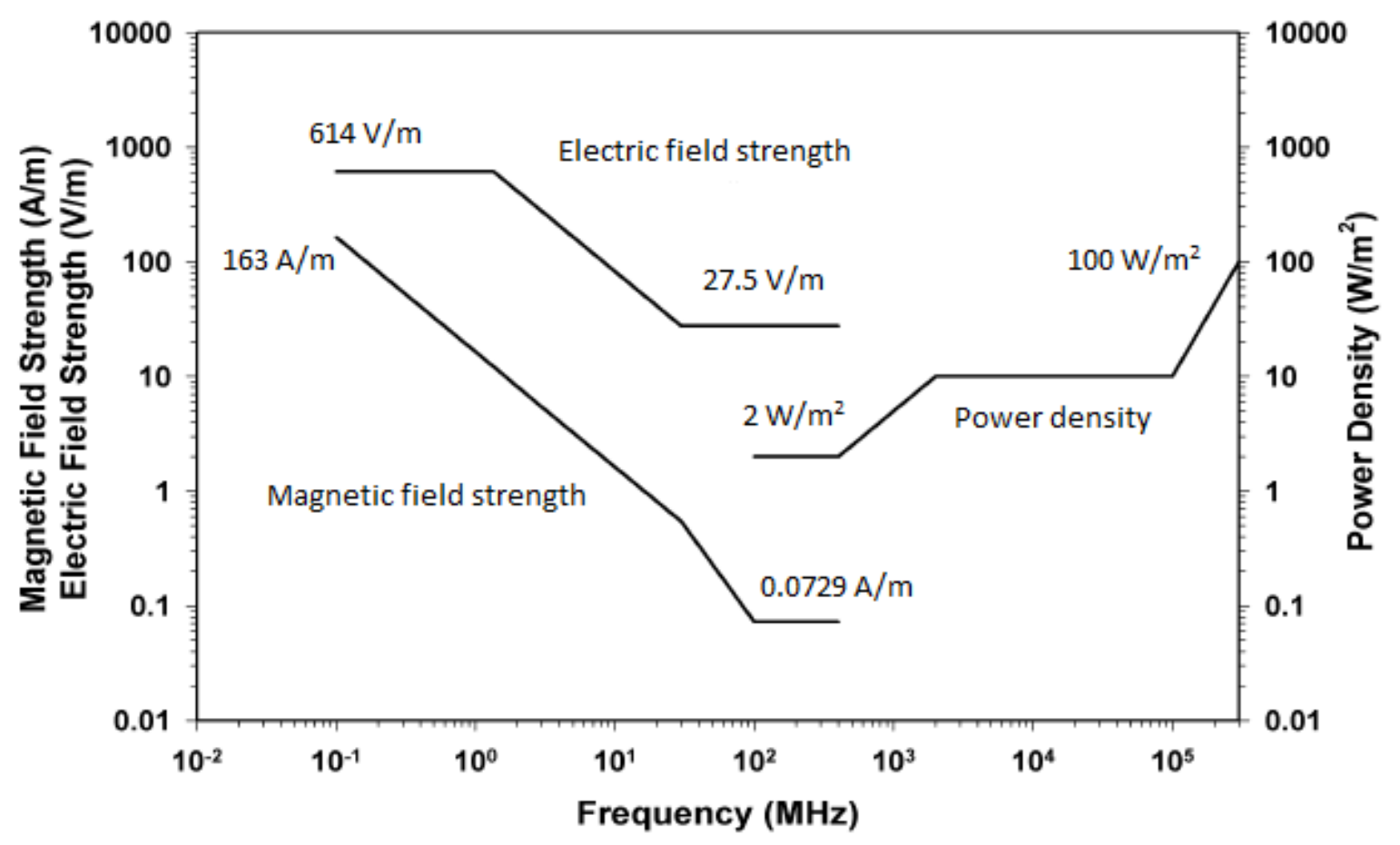

Fig.12 IEEE reference levels for exposure to time varying EM fields.

\section{Conclusions}

Near-field WPT has gaining momentum in commercialization and applications. This article addresses some current developments and issues of existing and emerging industrial WPT guidelines and standards. Comments and suggestions are offered to WPC and AFA for the evolving Qi standard and Rezence guidelines. For wireless charging of electric vehicles, the author points out several problems in the SAE 2016 guidelines and suggests an alternative approach that can eliminate a series of important problems such as relatively low energy efficiency associated with the long transmission distance, misalignment, reliability, ease of monitoring the conditions of the receiver pads, human exposure to magnetic field and presence of foreign objects and pet animals. In addition, more research should be diverted to study the effects of the electric and magnetic fields on the quantum biological levels of cells.

\section{Acknowledgement:}

This work was supported by the Hong Kong Research Grant Council under the project: 17255916.

\section{References:}

[1] Nikola Tesla, "High frequency oscillators for electro-therapeutic and other purposes", The Electrical Engineer. Vol. XXVI. November 17, 1898. No. 550.

[2] Nikola Tesla, "Transmission of electrical energy without wire", Electrical World and Engineer, March 5, 1904 [online] www.tfcbooks.com/tesla/

[3] M. Hutin and M. Leblanc, "Transformer system for electric railways", US patent 527857 , Oct. 23, 1894

[4] "Nikola Tesla 1857 - 1943", May 1943, Proceedings of the I.R.E., pp: 194 
[5] R. Lomas, "The Man Who Invented the Twentieth Century - Nikola Tesla - Forgotten Genius of Electricity", U.K., Headline Book Publishing, 1999

[6] G. B. Joung and B. H. Cho, "An energy transmission system for an artificial heart using leakage inductance compensation of transcutaneous transformer', IEEE Transactions on Power Electronics, Vol.13, No.6, 1998, pp. 1013-1022.

[7] A. Ghahary and B.H. Cho, "Design of a transcutaneous energy transmission systems using a series resonant converter", IEEE Power Electronics Specialists Conference, 1990, pp.1-8

[8] A.W. Green and J.T. Boys, “10k Hz inductively coupled power transfer - concept and control”, 1994 Power Electronics and Variable Speed Drives Conference, 1994, pp: 694-69

[9] G.A.J. Elliott, J.T. Boys and A.W Green, "Magnetically coupled systems for power transfer to electric vehicles", Proceedings of 1995 International Conference on Power Electronics and Drive Systems, 1995, Page(s): 797 - 801 vol.2

[10] Y. Jang and M. Jovanovic, "A contactless electrical energy transmission system for portabletelephone battery chargers", IEEE Transactions on Industrial Electronics, vol. 50, no. 3, pp. 520 - 527, Jun. 2003.

[11] C.-G. Kim, D.-H. Seo, J.-S. You, J.-H. Park and B. H. Cho, "Design of a contactless battery charger for cellular phone", IEEE Transactions on Industrial Electronics, vol. 48, no. 6, pp. 1238-1247, Dec. 2001.

[12] Yungtaek Jang; M.M. Jovanovic, "A contactless electrical energy transmission system for portable-telephone battery chargers", Twenty-second International Telecommunications Energy Conference, 2000. INTELEC., Pages: 726 - 73

[13] B. Choi, J. Nho, H. Cha, T. Ahn, and S. Choi, "Design and implementation of low-profile contactless battery charger using planar printed circuit board windings as energy transfer device", IEEE Transactions on Industrial Electronics, Vol. 51, No. 1, Feb 2004, pp. 140-147

[14] S.Y.R. Hui, "Planar inductive battery charger", UK Patent GB2389720B, 7 Sept. 2005.

[15] L. Cheng, J.W. Hay and P. Beart, "Contact-less power transfer", US Patent 6,906,495, June 14, 2005

[16] S.Y.R. Hui, "Planar Wireless Charging Technology for Portable Electronic Products and Qi", Proceedings of the IEEE [Invited Paper] Volume: 101, Issue: 6, 2013, Page(s): 1290 - 1301

[17] G. Covic and J.T. Boys, "Inductive Power Transfer", Proceedings of the IEEE [Invited Paper] Volume: 101, Issue: 6, 2013, Page(s): 1276 - 1289

[18] A. Kurs, A. Karalis, R. Moffatt, J. D. Joannopoulos, P. Fisher and Marin Soljac `ic', "Wireless Power Transfer via Strongly Coupled Magnetic Resonances”, Science, Vol. 317, July 2007, pp: 83-86

[19] S. Cheon, Y.H. Kim, S.Y. Kang, M. L. Lee, J.M. Lee, and T. Zyung, "Circuit-model-based analysis of a wireless energy-transfer system via coupled magnetic resonances", IEEE Trans. Industrial Electronics, vol. 58, no. 7, pp. 2906-2914, Jul. 2011

[20] C.J. Chen, T.H. Chu, C.L. Lin, and Z.C. Jou, "A study of loosely coupled coils for wireless power transfer", IEEE Trans. Circuits and Systems - II: Express Briefs, vol. 57, no. 7, pp. 536540, Jul. 2010.

[21] M. Kiani, and M.. Ghovanloo, "The circuit theory behind coupled-mode magnetic resonancebased wireless power transmission," IEEE Trans. Circuits Systems - I, vol. 59, no. 8, pp. 110, Aug. 2012

[22] S.Y.R. Hui, "Magnetic resonance for wireless power transfer [A Look Back]", IEEE Power Electronics Magazine, 2016, Vol: 3, Issue: 1, Pages: 14 - 31

[23] L. Cheng, J.W. Hay and P. Beart, "Contact-less power transfer", US Patent 6,906,495, June 14,2005 
[24] P. Beart, L. Cheng, and J. Hay, "Inductive Energy Transfer System Having a Horizontal Magnetic Field," U.K. Patent GB2399225, 2006.

[25] S..Y.R. Hui, "Planar inductive battery charger", UK Patent GB2389720B, 7 Sept. 2005.

[26] S.Y.R. Hui and W.C. Ho, "A new generation of universal contactless battery charging platform for portable Consumer Electronic equipment", IEEE Transactions on Power Electronics, Volume 20, Issue 3, May 2005 Page(s):620 - 627

[27] Wireless Power Consortium website: https://www.wirelesspowerconsortium.com/

[28] Menno Treffers, "History, Current Status and Future of the Wireless Power Consortium and the Qi interface specification", IEEE Circuits \& Systems Magazine, Vol.15, Issue 2, May 2015, pp: 28-31

[29] X. Liu, L. H. Swaans, K. W. Chan, H. K. Low, W. K. Chan, "Methods and systems for detecting foreign objects in a wireless charging system”, US 9178361, Sep. 27, 2012

[30] AirFuel Alliance website: http://www.airfuel.org/

[31] A4WP Wireless Power Transfer System Baseline System Specifications (BSS), Version 1.3, Nov. 05, 2014.

[32] R.J. Usselman, I. Hill, D.J. Singel and C. F. Martino, "Spin Biochemistry Modulates Reactive Oxygen Species (ROS) Production by Radio Frequency Magnetic Fields", PLOS, Vol.9, Issue 3, March 2014, pp:1-2

[33] Frank Barnes and Ben Greenbaum, "Magnetic Field Effects on Biology and Potential Health Effects Below the ICES and ICNIRP Reference Levels", IEEE Wireless Power Transfer conference, Boulder, N.C., USA, May 2015, Paper T5.8, pp:1-4

[34] http://standards.sae.org/wip/j2954/ http://standards.sae.org/wip/j2954/

[35] S.Y.R. Hui, "System and Method for Charging Electric Vehicles", US provisional patent application, 62/474,732, March 22, 2017.

[36] S.Y.R. Hui and S.C. Tang, "Planar Printed Circuit-Board Transformers with Effective Electromagnetic Interference (EMI) Shielding”, US patent US6,888,438, May 2005

[37] Qi Standard version 1.2.3, Feb. 2016, Wireless Power Consortium website

[38] International Communication on Non-Ionizing Radiation Protection (ICNIRP), "Guidelines for limiting exposure to time-varying electric and magnetic fields (1 Hz to $100 \mathrm{kHz})$, Health Phys. 2010 Dec;99(6):818-36

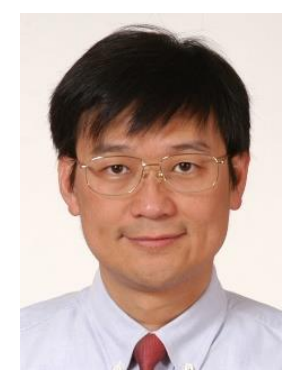

S. Y. (Ron) Hui (M'87-SM'94-F'03) received his BSc (Eng) Hons at the University of Birmingham in 1984 and a D.I.C. and PhD at Imperial College London in 1987. Presently, he holds the Philip Wong Wilson Wong Chair Professorship at the University of Hong Kong and a part-time Chair Professorship at Imperial College London.

He has published over 300 technical papers, including more than 220 refereed journal publications. Over 60 of his patents have been adopted by industry. He is an Associate Editor of the IEEE Transactions on Power Electronics and IEEE Transactions on Industrial Electronics, and an Editor of the IEEE Journal of Emerging and Selected Topics in Power Electronics. His inventions on wireless charging platform technology underpin key dimensions of Qi, the world's first wireless power standard, with freedom of positioning and localized charging features for wireless charging of 
consumer electronics. He received the IEEE Rudolf Chope R\&D Award from the IEEE Industrial Electronics Society and the IET Achievement Medal (The Crompton Medal) in 2010, and IEEE William E. Newell Power Electronics Award in 2015. He is a Fellow of the Australian Academy of Technological Sciences \& Engineering and a Fellow of the Royal Academy of Engineering, U.K. 